\title{
Good news is no news
}

\section{How can scientists use the media to give their side of the story to the public?}

John Emsley

alk to a chemist about the media and he or she will complain that their science gets a raw deal. And so it is, and has been for 20 years or more. A typical example in the United Kingdom is the Daily Mail, whose front page, one day in March 1996, shrieked "CHEMICAL TRAIN SMASH HORROR!" In fact, the chemical in question was carbon dioxide: a tank of it had ruptured and was "spewing gas all over the place", creating "a 3-ft deep mist". That was all - but it merited an alarmist headline. And there's the rub: chemical rubbish gets published while real chemistry goes unreported.

The subeditor who devised the above headline was catching the readers' attention with a carefully baited emotional hook, suggesting pollution and destruction. Pressure groups who seek to capture public notice are skilled in providing such hooks, often to publicize opinions that infuriate scientists with their misinformation and disinformation. Chemists suffer more than most. They are blamed by environmentalists for causing pollution, by alternative-health gurus for causing cancer, and by organicfood producers for contaminating crops. All these groups put out regular press releases, with excellent hooks.

Rational argument alone will not carry a message to the general public; it has to travel on the back of emotion. People will understand that medical or pharmacological advances offer a new treatment for a particular disease, but the information will be quickly forgotten unless the news has a visceral component that registers feelings such as fear for oneself or sympathy for others.

There can be various degrees of emotional involvement in a news item, ranging from the personal, through the societal to the global. A common ploy of the first type is to reveal a threat to a group we are bound to be sympathetic towards, such as babies, breastfeeding mothers or young children. Threats to pregnant women or to male fertility are

\section{fwe want sound}

\section{science to make the} headlines in a positive way, we need to think of how we package it. likely to hook the young, while risks of heart disease and cancer hook those who are older. In the societal category the targets are broader and consist of threats to food, wealth and health, while for global hooks the emphasis is on deprived people in developing countries, or on wildlife, or on the planet as a whole.

There is no reason why stories from scientists should not use the same emotional hooks to get their message across. For example, advances in agrochemical fertilizers and pesticides can be justified as saving wildlife because they allow more human food to be produced on less land, thereby reducing the destruction of natural habitats. A new drug may have economic benefits, for example by reducing the need for a stay in hospital, but it would be better to say that it will transform the health of the afflicted and concentrate on their currently blighted lives.

All this may sound a bit contrived, and you may think that if people don't want to read about sound science, then it's their loss and that's the end of the matter. But the mainstream sciences will never regain the standing they once had if we continue to communicate badly. Nor is it a hopeless task. Even chemistry has had its news successes, the most notable being Viagra, which captured wide media attention in the late 1990s. There, of course, the hook was the most powerful of all: sex.

Yet I am sure that many molecular scientists will remain unconvinced by the need to be pro-active in communicating. It might help them if I draw an analogy between communication and oxidation. No matter how strong the oxidizing agent (the information) it cannot attract electrons (attention) from some atoms or molecules. What may be needed is something that starts the process by tempting an electron into an outer orbital (the hook).

Even so, putting across good news has an added energy barrier to surmount: only bad news is good news as far as the popular press is concerned. Those who demonize the products of science have become skilled in the art of writing press releases full of doom and gloom. "Babies at risk from PVC toys" is a typical example which ran in the media last Christmas, and used a well-tried hook. The publicists of organizations issuing such warnings can generally come up with skilfully contrived phrases that even enter everyday speech, such as 'gender-benders', 'Frankenstein foods', 'cancer on tap' and 'artificial fertilizers' - all highly emotive, and all misleading.

If we want sound science to make the

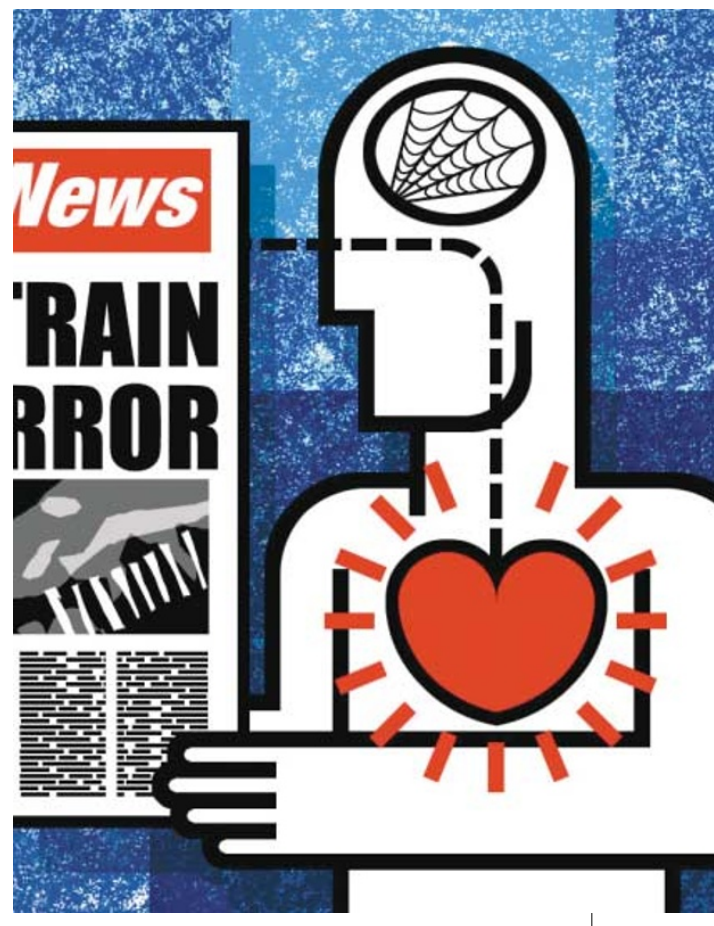

headlines in a positive way, we need to think of how we package it. OK, you've done some brilliant research and now you want your company, university or research institute to issue a press release about it. Of course, you can simply describe what you have done, say who funded the research and what its aim was, add a brief description of yourself and give a contact number, and wait for the journalists to ring you. And wait, and wait, and wait ... what your story lacks is a good hook.

So what are the good hooks? The top three are sex, money and health. Link your story to one of those and you're away. The newspaper subeditors who devise headlines will have no difficulty in catching the reader's attention with SEX, CASH and CURE. Other hooks can be almost as effective. Have your research findings explained the unexplained? Or are they contrary to expectations? These make intriguing hooks with headline words such as CLUE and SHOCK. A local connection, a research first, possible job creation and even national pride are also useful areas to emphasize.

Failing any of these, you should try to suggest that your work will provoke controversy. In the United Kingdom, headline writers are wedded to the hook words of confrontation, such as FURY, FEAR, STORM, ROW and LOOMS. For example, to create a news item about this article, I would find someone who disagrees with something I have said, and then head a press release about it with the phrase: NEWS SPIN ROW LOOMS. Shock horror - it can be done.

John Emsley is science writer in residence in the Department of Chemistry, Cambridge University, Lensfield Road, Cambridge CB2 1EW, UK, and author of Nature's Building Blocks: An A-Z Guide to the Elements (Oxford University Press). 